\title{
Solid Waste Management Practices and Challenges: The Case of Halaba Town in Southern Ethiopia
}

\author{
Alamudin Kufa Kedir ${ }^{*} \quad$ Temesgen Eliku ${ }^{2} \quad$ Getachew Demie Gebre ${ }^{3}$ \\ 1.Natural Resource Management Program, College of Agriculture and Natural Resource, Werabe University, \\ P.O Box 46, Werabe, Ethiopia \\ 2.Environmental Science Program, College of Natural and Computational Science, Wollega University, P.o box \\ 395, Nekemte, Ethiopia \\ 3.Environmental Science Program, Wondo Genet College of Forestry and Natural Resource, Hawassa \\ University, P.o box 128, Shashemene, Ethiopia
}

\begin{abstract}
Solid waste, which is a consequence of day-to-day activity of human kind, needs to be managed properly. Due to rapid increase in urbanization and population, the generation rate of municipal solid waste in Halaba town is also increasing due to which the town is facing several difficulties in providing proper solid waste management services to its population. Accordingly, the objective of this particular study was to assess the existing solid waste management practices and challenges in Halaba town in southern Ethiopia. Questionnaire, interview, field measurement and field observation were the instrument employed to collect valid data. Data was gathered from 150 randomly selected sampled households using open ended and close ended questionnaire and from purposely selected key informants using semi structured interview. Based on the findings of this study, the households' solid waste generation rate is $0.271 \mathrm{~kg} / \mathrm{person} /$ day. The result showed that waste composition in the study area was dominated by a high organic content; food waste and vegetable peelings $(43.18 \%)$ followed by ash and dust (35.81\%) leaves, wood scarp, paper and cardboard (11.88\%) and metal, glass, ceramics, plastics and textiles $(8.52 \%)$. The study revealed that only $18 \%$ of the household's solid waste was collected by municipality. As a result of this, huge amounts of uncollected solid wastes are indiscriminately disposed in unauthorized areas. Finally, the study indicated the weak financial status of the municipality to provide adequate solid waste management services along with low awareness of the community were the series problem that challenges the practice of solid waste management system in Halaba town. Therefore, adoption of sustainable solid waste management systems (reuse, recycle and composting) through awareness creation campaign to enable the people aware of the importance of safe solid waste disposal for their environment and health should be encouraged.
\end{abstract}

Keywords: Household, Key informants, Solid waste generation rate, Solid waste management

DOI: 10.7176/JEES/9-9-03

Publication date:September $30^{\text {th }} 2019$

\section{INTRODUCTION}

Waste is any substance that is discharged, emitted or deposited in the environment in such a volume constituency or manner as to cause an alteration in the environment. While solid waste is any material which comes from domestic, commercial and industrial sources arising from human activities which has no value to people who possess it and is discarded as useless (Takele, 2004). In the early days, waste disposal did not pose difficulty as habitations were sparse and land was plentiful. However, from the time humans began to congregate in tribes, villages and communities the accumulation of waste become a problem.

Solid waste, which is a consequence of day-to-day activity of human kind, needs to be managed properly. Particularly, waste volumes have increased in urban area due to the rapid growing urban population, concentration of industries, consumption of residents and inadequate finance and facilities to manage waste collection and disposal (National Environmental Management Authority [NEMA], 2007). This state of affairs has led to the volume of solid waste generated to go beyond what the available facilities can accommodate.

Solid waste management (SWM) thus emerged as an essential, specialized sector for keeping cities healthy and livable. Solid waste management refers to source separation, storage, collection, transportation and final disposal of waste in an environmentally sustainable manner (Feleke, 2015). In the light of this, municipal solid waste management is an important environmental health service and an integral part of basic urban services. This is because, the health implications of poor waste management can be very damaging to the people exposed to these unsanitary conditions. Diseases such as cholera, typhoid, dysentery and malaria are all related to the practice of poor waste management (Javaheri, 2006). This can result in the loss of human resources needed in the development of the country.

Urban waste management has been a challenge for municipalities and urban governments in the Africa, largely due to poor infrastructure, bureaucratic competence and limited institutional capacity of the municipalities. Municipalities throughout Ethiopia are not free of these problems as they have been facing major challenges with solid waste collection and landfill management. The management approaches, methods and techniques employed 
in waste management by municipal have been unsuccessful. Moreover in comparison with other public sectors it has been observed that sectors dealing with waste management have often received little attention from the governments (Yeballework, 2014).

Similarly, Halaba is one of the town by which proper provision of solid waste management services is still unsatisfactory and incomplete. In Halaba, illegal dumping of waste on open areas, street, in ditches, river banks is considered as routine task of residents. The efforts made by the municipality to change the situation in the town are also insufficient as it compared to the extent of the problem. In addition, the town is also characterized by rapid population growth. Such rapid increase in population together with rapid development of the town has produced increasing volumes of solid waste and inturn leads to greater infrastructural demand, institutional setup and community participation for its management. But the town sanitation and beautification department which runs the solid waste management activities of the town could not fulfill the above requirements. Previously, no study has been done on solid waste management practices and challenges in the town. The aim of this study was therefore to assess solid waste management practices and challenges of the town side by side with household solid waste management practices.

\section{MATERIALS AND METHODS}

\section{Description of the Study Area}

The study was conducted in Halaba town which is the administrative center of Halaba special woreda (district), southern Ethiopia. Geographically, the town is located on latitude $7^{0} 18^{\prime} 44^{\prime \prime}$ north and longitude $38^{0} 05^{\prime} 21^{\prime}$ " east (Figure 1). The town is located at $315 \mathrm{~km}$ from south of Addis Ababa and $90 \mathrm{~km}$ from south of Hawassa, capital of southern Ethiopia and has a total area of 2,320 ha. It is divided into two (2) sub cities. The town sits on the left bank of the Blate River, with an elevation of $1,726 \mathrm{~m}$ above sea level. The study area is characterized by rapid population growth. Currently, the total population of the town is 40,447 of which 21,844 are females and 18,603 are males according to Halaba town health office annual report (2017).

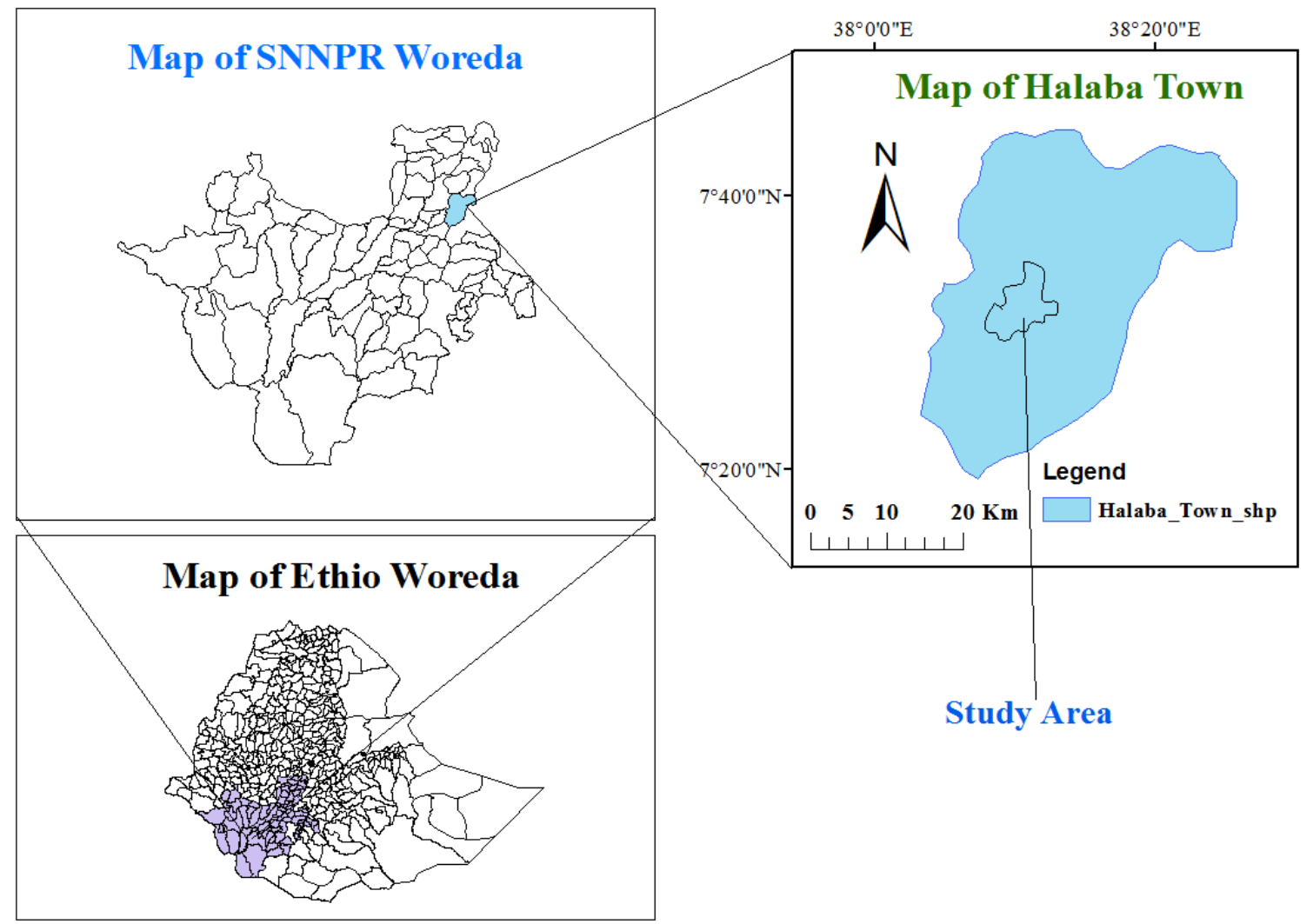

Research Design

Figure 1. Location map of Halaba town.

The research design which has been used in this study is descriptive research design because it is suitable for describing the existing situation (present situation) narrating facts and investigating phenomena in their natural setting (Koul, 1996). Thus, descriptive survey approach was employed in the study.

Sources of Data

To achieve the intended objective of the study, relevant data required for this study were collected from both primary and secondary sources. Primary data for this study was collected from household survey, purposively 
selected key informants (KIs) interviews, field measurement and field observations. Moreover, secondary data providing relevant information to this study was obtained from different sources related to the issues under study and those found in sanitation, beautification and parks development department (SBPDD) of the municipality and the health office of the town. In addition, published and other relevant materials were reviewed to obtain secondary data.

\section{Sampling Techniques and Sample Size}

In any sample survey, sample size determination is an important step. A total of eight thousand two hundred fifty four $(8,254)$ households residing in the five/5/ kebeles (the lowest administrative unit in Ethiopia) of the town were the target population of the survey. Sample size (n) of households that participate was determined by using a sample technique (formula), which was developed by Cochran (1977) given as:

Where;

$$
\mathrm{n}=\frac{\mathrm{NZ}{ }^{2} \mathrm{PQ}}{\mathrm{d}^{2}(\mathrm{~N}-1)+\mathrm{Z}^{2} \mathrm{PQ}}
$$

- $\quad \mathrm{P}=$ Housing unit variable (residential houses)

- $\quad \mathrm{Q}=1-\mathrm{P}$ (non residential houses)

- $\quad \mathrm{N}=$ Total number of housing units $(8,254)$

- $\mathrm{Z}=$ Standardized normal variable and valued that corresponds to $95 \%$ confidence interval equal to 1.96

- $\mathrm{d}=$ Allowable error $(0.05)$

According to data obtained from Halaba town health office (2017), there are about 8,254 housing units (N): out of these more than $90 \%(\mathrm{P})$ are of residential and the rest $10 \%(\mathrm{Q})$ is for commercial activities and offices.

$$
\mathrm{n}=\frac{8254 *(1.96)^{2} * 0.9 * 0.1}{(0.05)^{2} *(8254-1)+(1.96)^{2} * 0.9 * 0.1}=136
$$

Therefore, the result $\mathrm{n}=136$ was the minimum reliable sample size of housing units. To be safe and accurate the sample size was increased to 150 by considering $10 \%$ adjustments and correction factor. By using simple random sampling 150 samples were selected. This was done by lottery system, where the households (HHs) house number were written on pieces of paper, rolled out and one was randomly picked and continue until the required number of households was selected. If the selected housing units were not serving as a home or just demolished for purpose of condominium or households were non-cooperative; the next housing number was selected. Generally 150 for questionnaire and 12 for interview totally 162 samples were used for the study. After this, proportional percentage of samples within each stratum to decide the number of samples that was taken from each stratum as summarized in Table 1.

Table 1. Sample selection with proportional allocation

\begin{tabular}{llccc}
\hline S. No & Kebeles (wards) & $\begin{array}{c}\text { Total households } \\
(\mathrm{N})\end{array}$ & $\begin{array}{c}\text { Proportional } \\
\text { percentage }\end{array}$ & $\begin{array}{c}\text { Sampled } \\
\text { household }\end{array}$ \\
\hline 1 & Danabe Lama (01) & 2139 & 26 & 39 \\
2 & Murasa bar (02) & 2068 & 25.33 & 38 \\
3 & Lenda bar (03) & 1934 & 23.33 & 35 \\
4 & Wanja bar (04) & 1270 & 15.33 & 23 \\
5 & Mehal Arada (05) & 843 & 10 & 15 \\
& Total & 8254 & 100 & 150 \\
\hline
\end{tabular}

Source: Halaba town health office (2017).

Data Collection Instruments

To obtain sufficient and reliable information required for the achievement of the intended objectives of this study from both primary sources and secondary sources, the following data collection tools were employed.

\section{Questionnaires}

The questionnaire with both open ended and close ended questions were prepared. The questionnaire was prepared in English language and to avoid language barriers it was translated to local language. After preparation, around 15 questionnaires were randomly distributed as pretest in order to correct unclear and misleading questions. Then, it was distributed to randomly sampled households.

\section{Interviews}

Key informant's from each category for the semi structure interview was selected using purposive sampling method. Under study interview was made with one SBPDD official, three health experts, three solid waste managers, two environmental protection agency workers and three SBPDD workers. This is because of the fact that the selected key informants assumed to be well aware of the problem and could provide the relevant information required for the achievement of the intended objectives of the study.

\section{Field measurement}

Out of 150 households 30 households were selected randomly depending on their income level. This is because the rate and quantity of solid waste production of households is a direct reflection of their income level or economic 
performance (George, 2015). In order to have an average result in cases of differences in waste generation between days, collection and sorting of solid wastes from the participating households has been conducted for consecutive days of one week. The sampling program was extended over eight consecutive days. A waste collected on the first day was discarded, as it might have been the accumulation of many days.

\section{Field observations}

In view of supporting and realizing the information obtained from the sampled households and key informants, field observation was also conducted by using check list.

\section{Data Analysis}

Arc map 10.2 Software was used to extract the map of the study area. The statistical package for social sciences (SPSS) version 24 and Microsoft excel version 2007 were used to process the quantitative data. The quantitative data mainly obtained using close-ended questionnaire was analyzed by simple descriptive statistics like percentage, frequency, average and the result was summarized in the form of table, graph and figures. The qualitative data /perception, opinion, and attitude) mainly obtained using open ended questionnaire and semi structured interview including the researcher's observation were analyzed, described and interpreted in the form of narration.

\section{RESULTS AND DISCUSSIONS}

The rate of solid waste generation in the town is very fast and accounts about 8,880 kg per day (SBPDD, 2017). As a result, $(78.67 \%)$ of the residents considered solid waste management as a necessary and vital urban service just like other services such as road, water and electricity. On the other hand, respondents were also asked to evaluate the effort made by the municipality to provide efficient municipal solid waste management service compared with other services in the town. Accordingly, the majority $131(87.34 \%)$ of them responded that municipality has made weak effort.

\section{Municipal solid waste sources and their solid waste generation}

Municipal solid waste consists of highly heterogeneous mass of discarded materials from urban residences, commercial establishments, institutions, street sweepings and light industrial activities. Similarly, according to Halaba town SBPDD report (2017) there are five major sources of municipal solid waste of the town. Based on this report, the daily total solid waste generation of these sources is about $8,880 \mathrm{~kg}$.

Table 2. Major solid waste sources and their daily generation of Halaba town in 2017

\begin{tabular}{clcc}
\hline S. No & Source of solid waste & Daily amount of solid waste generated (in kg) & Percentage \\
\hline 1 & Residential areas & 5683.2 & 64 \\
2 & Commercial areas & 1864.8 & 21 \\
3 & Street sweeping & 710.4 & 8 \\
4 & Institutions & 532.8 & 6 \\
5 & Small scale industry & 88.8 & 1 \\
& Total & $\mathbf{8 8 8 0}$ & $\mathbf{1 0 0}$ \\
\hline
\end{tabular}

Source: SBPDD report, 2017

Table 2 revealed that, (64\%) of annual solid waste of Halaba town is generated from residential areas. Even if huge amount of solid waste of the town is generated from this source, the town SBPDD does not gave much weight for it in planning and implementation process of municipal solid waste management.

\section{Solid waste generation rate of households}

In order to examine the association between income levels and rate of solid waste generation the households also stratified into three categories as high, middle and low income group households (Halaba town socio economic data office, 2017). The findings have been summarized in the following Table 3.

Table 3. Solid waste generation rate of households in 2017

\begin{tabular}{lcccc}
\hline $\begin{array}{l}\text { Income } \\
\text { Groups }\end{array}$ & $\begin{array}{c}\text { No of sample } \\
\text { HHs }\end{array}$ & Family size & Quantity $(\mathrm{Qt}) / \mathrm{HH} /$ day $(\mathrm{kg})$ & $\begin{array}{c}\text { Generation rate of a group } \\
\text { Qt/person/day }(\mathrm{kg})\end{array}$ \\
\hline Higher & 6 & 36 & 12.86 & 0.3572 \\
Middle & 13 & 73 & 20.99 & 0.2875 \\
Lower & 11 & 60 & 12.03 & 0.2005 \\
Total & $\mathbf{3 0}$ & $\mathbf{1 6 9}$ & $\mathbf{4 5 . 8 8}$ & $\mathbf{0 . 2 7 1}$ \\
\hline
\end{tabular}

Source: Field survey data, 2017

The Table 3 shows that the average amount of solid waste generation from the surveyed households was $(0.271 \mathrm{~kg} / \mathrm{person} /$ day $)$. When $0.271 \mathrm{~kg} / \mathrm{person} /$ day generation rate of Halaba town households is compared with other Ethiopian towns such as Robe $0.261 \mathrm{~kg} /$ person/day (Duguma et al., 2018), Dessie town $0.231 \mathrm{~kg} / \mathrm{person} / \mathrm{day}$ (Solomon, 2011) and Nekemte town $0.29 \mathrm{~kg} /$ person/day (Desalegn, 2017), the findings are in agreement with the present study.

Since, income and family size are the most important factor influencing the generation rate of solid waste at a particular area (George, 2015); their relationship was tested using correlation and linear regression model. 
Table 4. Correlation between income and solid waste generation

\begin{tabular}{llcc}
\hline & & Qt/HH/day(kg) & Income of HH (birr) \\
\hline Qt/HH/day(kg) & Pearson Correlation & 1 & $.724^{* *}$ \\
& Sig. (2-tailed) &. & 0 \\
Income of & $\mathrm{N}$ & 30 & 30 \\
HH(birr) & Pearson Correlation & $.724^{* *}$ & 1 \\
& Sig. (2-tailed) & 0 &. \\
\hline
\end{tabular}

** Correlation is significant at the 0.01 level (2-tailed).

The result in Table 4 indicated that daily household solid waste generation was positively correlated with the income (i.e. 0.724). It means that, as the household's income increase, the quantity (Qt) of waste generated per day also increases. George (2015) observed that an increase in income leads to an increase in the amount of waste generated per day. He also confirmed that increase in income affects life style of households as well as the consumption habit. This is as a result of higher income and a greater purchasing power. In this event they generate more waste than low income inhabitants. Similar study conducted by Mengie (2015) also revealed that, household's income is strongly correlated with solid waste generation.

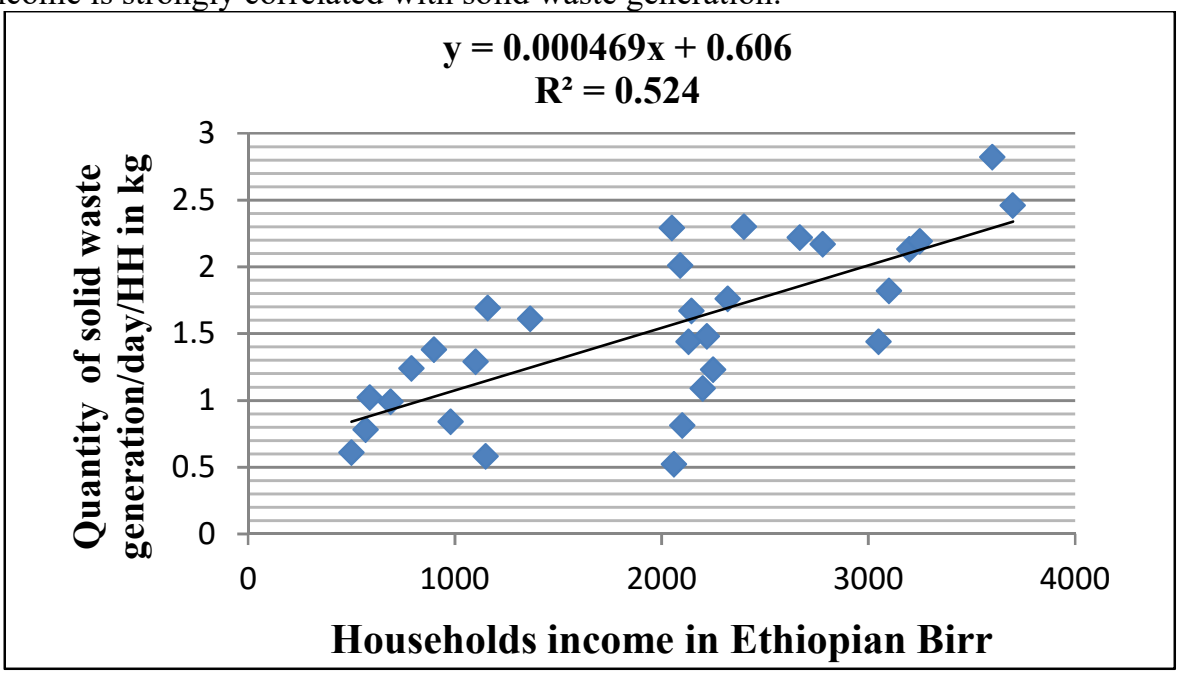

Figure 2. Linear regression analysis of household income and solid waste generation.

Table 5. Correlation between family size and solid waste generation

\begin{tabular}{llcc}
\hline & & Family size & Qt/HH/day $(\mathrm{kg})$ \\
\hline Family size & Pearson Correlation & 1 & $.809^{* *}$ \\
& Sig. (2-tailed) &. & 0 \\
& $\mathrm{~N}$ & 30 & 30 \\
Qt/HH/day $(\mathrm{kg})$ & Pearson Correlation & $.809^{* *}$ & 1 \\
& Sig. (2-tailed) & 0 & 30 \\
\hline
\end{tabular}

** Correlation is significant at the 0.01 level (2-tailed).

Similarly family size was also positively correlated with waste generation at the household level in the present study (i.e. 0.809) (Table5). It means that, increase in household members leads to increase in resource consumption resulting increase in waste generation at their houses. The study conducted in Cameroon also indicated that, family size is positively correlated to the amount of waste generated/day in a household (George, 2015). 


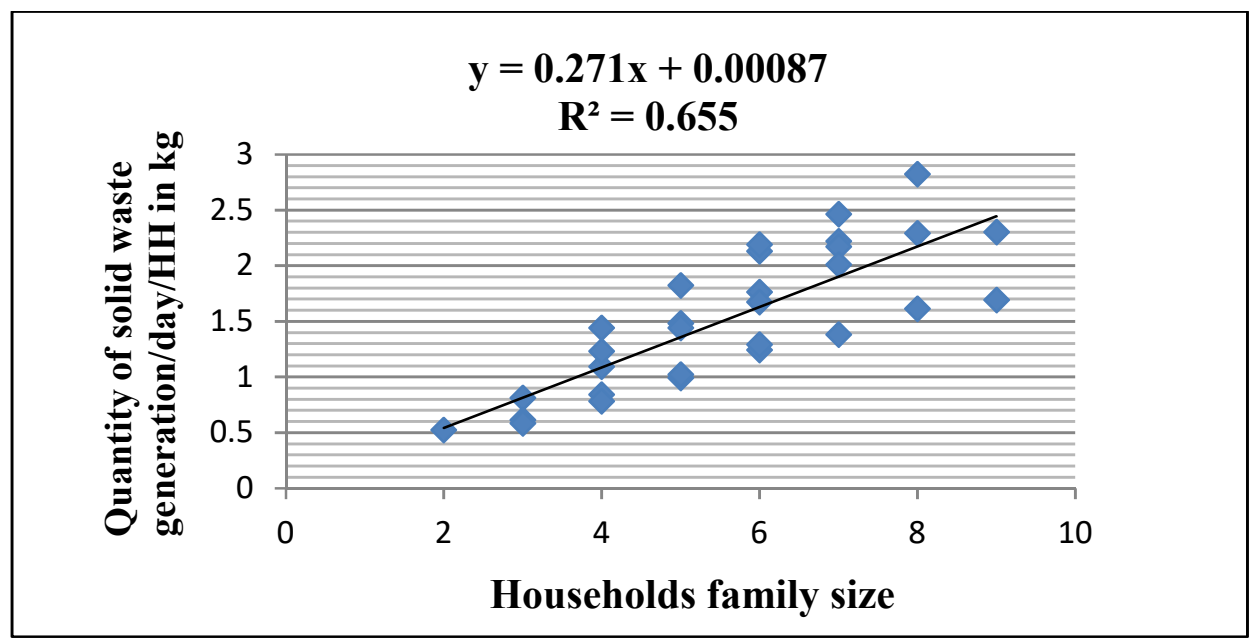

Figure 3. Linear regression analysis of household size and solid waste generation.

\section{Composition of municipal solid waste of the town}

The result of the survey in the study area showed that municipal solid waste was an aggregate of all substances ready for disposal. But commonly urban wastes can be subdivided into two major components called biodegradable and non biodegradable. In the same manner, biodegradable and non biodegradable solid waste was observed in the study households. Beside these, construction and demolition waste that is generated during the course of repair and construction activities constituting sands, stones, wood and so forth are also observed in the town.

Table 6. Composition of residential solid waste in 2017

\begin{tabular}{llcc}
\hline Category & Types of solid wastes & Qt/person/day in kg & $\begin{array}{c}\text { Percentage } \\
\text { Share }\end{array}$ \\
\hline Biodegradable & Food waste and vegetable peelings & 0.1172 & 43.18 \\
Solid waste & Leaves, wood scarp, paper and cardboard & & 11.88 \\
& & 0.0322 & 35.81 \\
Non & Ash and dust & 0.0972 & 5.2 \\
Biodegradable solid & Metal, glass and ceramics & 0.014 & 3.92 \\
waste & Plastics and textiles & 0.0106 & $\mathbf{1 0 0}$ \\
& Total & $\mathbf{0 . 2 7 1}$ & \\
\hline
\end{tabular}

Source: Field survey data, 2017

According to the study result high composition of solid waste were biodegradable (food waste and vegetable peelings $43.18 \%$, and leaves, wood scarp, paper and cardboard $11.88 \%$ ) such kind of waste can be turned into compost or organic fertilizer (Table 6). A high organic content has been reported by many authors in many different countries and cities such as: Indonesia (74\%) (Walhi, 2001); Nigeria (52-65\%) (Imam et al., 2007) and Debre Berhan, Ethiopia (80\%) (Solomon et al., 2016)

The ash and dust proportion of the domestic waste of the area was also high and this was seemingly due to the use of charcoal and wood as a major source of energy. This is directly related to the poor socio economic condition of the households to utilize other energy sources like electricity as well as due to the poor housing condition of the households. Most of the households used combustible materials like wood and charcoal for energy. The least solid wastes in terms of weight are metal, glass, ceramics and plastic wastes. This is because metal can be reused repeatedly and it can be recycled to other durable useful materials.

Solid Waste Storage Facility and its Handling

The result of the survey indicates that, solid waste storage and handling practice of Halaba town was carried out by two categories.

Primary solid waste storage facilities and their handling

Residents of Halaba town used different type of storage materials in their compound which is stationary like pit and portable like sack. The types of storage materials used by households are different. This is mainly because the nature of storage material of households depends on space available for placement of the storage materials and economic power of solid waste generators (Solomon, 2011). The result was shown in the following Figure 4. 


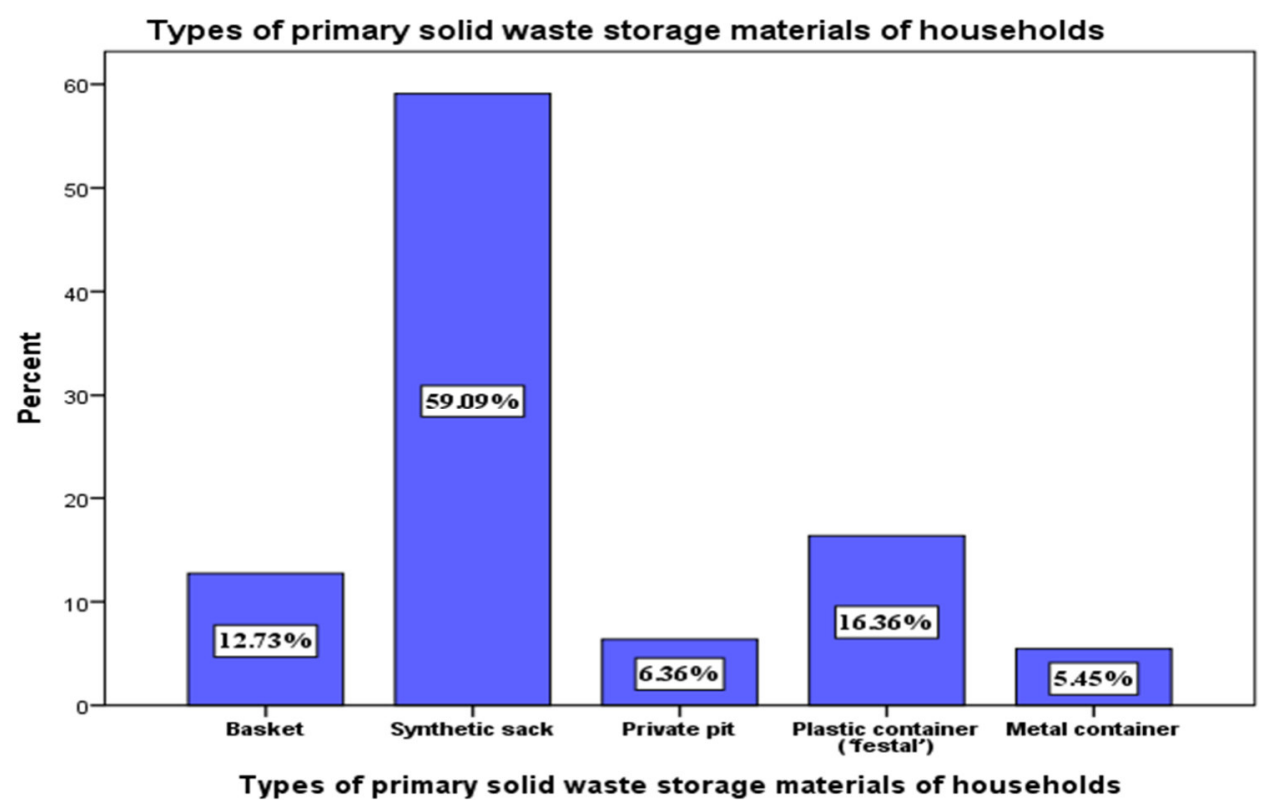

Figure 4. Types of primary solid waste storage materials of households

As observed in Figure 4, majority of households (59.09\%) stock up their solid waste in sack (Madaberia). This is highly related with the least cost of sack, easily availability in the market and its suitability for holding large volume of solid wastes. Next to sack, about $16.36 \%$ of households use plastic container (festal) followed by basket $(12.73 \%$ ) because of their frequent but low generation of waste and economical power to utilize replicable storage materials such as plastic bags. Following these there are households that use private pit (6.36\%) as storage material of solid waste in their home. This is due to availability of space in their compound and households need to prepare fertilizer for vegetable growing. But, the least used storage material is metallic container (5.45\%). This is essentially because of its difficulty for transportation, high cost and low access in market. Mohammed (2015) generated similar observation in the research done in Gondar town, Ethiopia. He stated that the majority of households put up their solid waste in sack.

\section{Secondary solid waste storage facilities and their handling}

Until early 2017, Halaba town SBPDD put 10 public solid waste containers in different areas of the town where frequent illegal dumping of waste was mostly occurred, and in areas where high population density is assumed to exist. But this operation caused odor and dust problems. This is mainly due to absence of frequent collection of those public solid waste containers and misuse of the society. Similarly, Asmamaw et al. (2017) observed the same problem in the Debra Berhan town, Ethiopia. He point out that the environment condition is very worse due to absence of frequent collection of waste from public containers in the town.

The sites are found at the edge of main roads in order to make such places accessible for transportation. However, in many cases those transfer stations are not well designed, not protected from rain and sun. So, those sites are created bad smell, unsightly urban picture and deterioration of the environment. This is supported by Geofrey (2016) indicated that, inadequate municipal solid waste management is certainly one of the contributing factors to the degradation of the environmental quality.

\section{Solid Waste Sorting Activities in Halaba Town}

As it was tried to observe households solid waste separation activities in the town, only solid wastes that are sellable to Quraleos, exchangeable to Liwach and to some extent organic wastes are separated. Supporting the observation, response of sample respondents shows that about $58.67 \%$ of them are separately store solid wastes which are sellable to "Quraleos" and exchangeable with "Liwach". "Korales" a person who move through the city to buy recyclable items such as glass, plastic, tin cans, metals, shoes etc. from different houses, hotels, restaurants, repairs services and sell them to small recyclers and industries. There are also people engaged in similar types of job known locally as "Liwach" who go around the city and exchange used clothes and shoes with new household utensils and sell them to low-income people.

The dominant types of such wastes include: metals, old shoes, plastic jar, glass, bottles and electronic wastes. Households' awareness about usefulness of such discarded wastes for Quraleos and Liwach together with their low economic performance led households to separately store such wastes and generate income and new equipments to their house. With similar study, Achi et al. (2012) reported that about $56 \%$ of the households sort their municipal solid waste (due to financial benefits as there is a company that pays for sorted plastic bottles). Finding in Dessie town, Ethiopia also showed that, about $62.76 \%$ of the household's separately store their solid at households level (Solomon, 2011). 


\section{Labors Available for Daily Collection of Solid Wastes}

Safe and environmentally sound solid waste management system requires various infrastructures and facilities to be fulfilled. In addition, availability of labors in charged with daily collection of wastes generated by the community and engaged in street sweeping are also equally important (Feleke, 2015).

Table 7. Preference of the respondents for and against available labors

\begin{tabular}{ccc}
\hline Responses & Frequency & Percent \\
\hline Yes & 11 & 7.3 \\
No & 139 & 92.7 \\
Total & 150 & 100.0 \\
\hline
\end{tabular}

In Table 7, the responses of most households 139(92.7\%) showed that there was no labor in charged with daily collection of solid waste. However, 11(7.3\%) of them responded as there was labor engaged with daily collection of solid wastes in the town. Most of the respondents replied "No" and they gave their justification that they dispose their solid waste around their home by using ordinary open burning and open dumping.

Even though some households out of the total respondents responded as there is labor in charged with daily collection of solid wastes, the response gained from the municipality of the town and the observation made affirmed the absence of labor engaged with daily collection of solid wastes in the town.

\section{Solid Waste Disposal Practices in Halaba Town}

Households' solid waste disposal practices

In order to assess the routine method of solid waste disposal practices of households and to know the destination of uncollected solid wastes, the sample respondents were asked about their common disposal system. The survey result looks like the following.

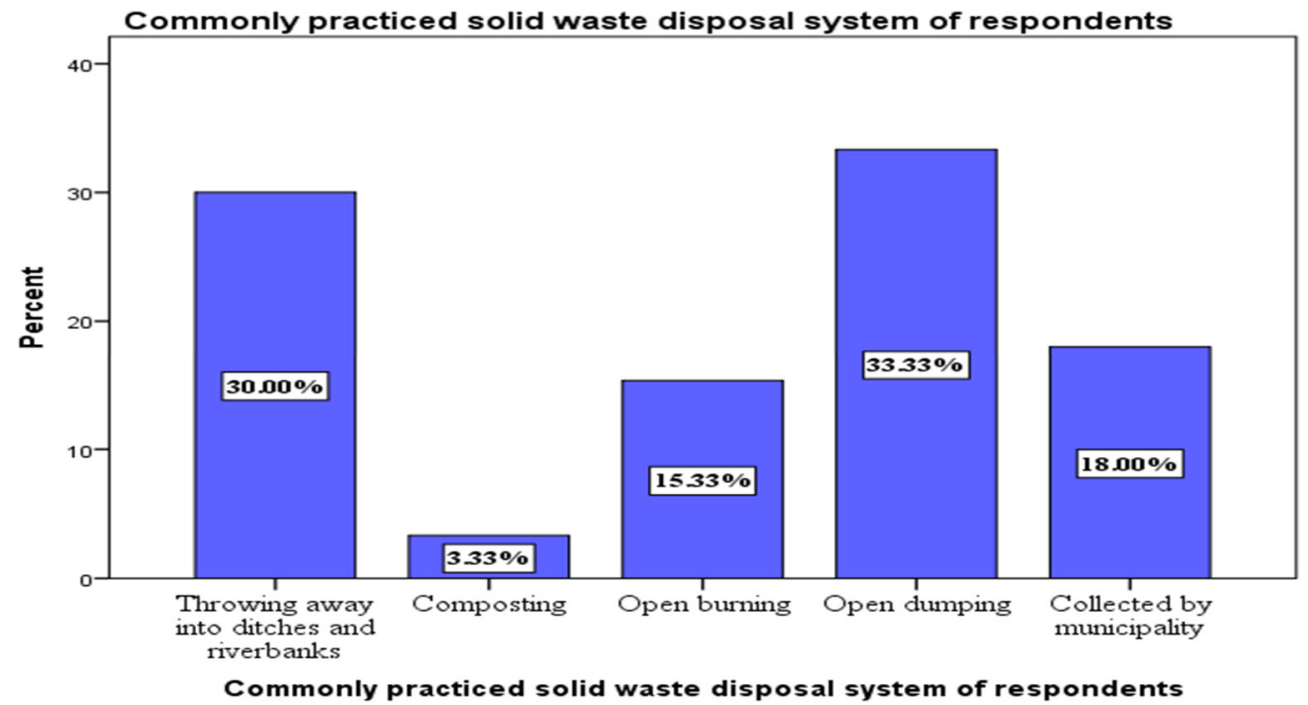

Figure 5. Households solid waste disposal practices

With regard to composting, the households practicing composting are very few. In addition only $18 \%$ of the household's solid waste was collected by municipality (Figure 5). While it is observed in Figure 5, quit large numbers of household's preferred improper and unauthorized solid waste disposal practices. This confirmed that the destination of the majority of uncollected solid wastes of households are roads, nearby ditches, bridges, and open areas. This agrees with the findings of other study conducted by Mohammed (2015). With Similar research work Solomon et al. (2016) indicated that, $75 \%$ of the respondents in Debre Berhan city, Ethiopia disposed waste in unauthorized places. In addition, the studies conducted by Aboma and Uttama (2013) in Shambu town, Ethiopia also reported that open-dumping and open-burning are the primary disposal system used by the residents of the town.

\section{Halaba town solid waste disposal practices and existing situation}

Proper solid waste management also requires proper disposal of waste in a proper place. As Yirgalem (2005) indicated, most of the African countries use uncontrolled open dumping and poor management of the site. Likewise, Halaba town solid waste disposal site and its management is inadequate and below the standard. In general the information obtained from all target population i.e. households, key informants and the observation made indicated that the disposal method practiced in the town is open dumping which is capable of causing various health and environmental problems.

Due to high methane gas in the disposal site, there is frequent fire which is a threat to human safety and cause of air pollution. Furthermore, different types of wastes should be disposed separately especially hazardous waste 
(Mengie, 2015). In Halaba town disposal site there is no solid waste separation and all types of wastes are disposed at a single site. In addition to this, odor is also another problem at the disposal site which diminishes the quality of fresh air in the surrounding area and causes residents be affected by different respiratory diseases. Hence, the disposal site is open to human, scavengers and animals. This situation caused solid waste scattering to the surrounding and posing health risk on the local community.

Landfill site selection involves proper study of the site in relation to its topography, slope, permeability, hydrology, accessibility, distance from incompatible land uses and acceptance by the local community (Guerrero et al., 2013). In this regard, the disposal site is not appropriate in any of the criteria. Therefore, the municipality and the community need to change those environmentally hazardous ways of solid waste disposal into more accepted and sanitary ways of solid waste disposal methods such as sanitary landfill and composting.

\section{Challenges Linked with SWM System in Halaba Town}

Regarding the factors behind the poor SWM system of the town, responses from the sampled households, KIs and the observation made revealed the following major factors.

\section{Financial factors}

Sanitation and beautification staff of the municipality revealed that, above all is a financial problem. With growing urban population municipality fails to provide service to all urban dwellers, as a result currently municipality is facing challenges in providing efficient municipal solid waste management.

In addition to this, information obtained from other key informants also revealed that the problem of finance is very acute. There is inadequate and unequal distribution of annual budget for the sectors. The finance source of the municipality which depends on the revenue to provide public services was weak. Koyachew (2016) observed the same problem in the city of Bahirdar, Ethiopia. He identified that financial aspect as a main hindering factor which determines the sustainability of effective solid waste management in Bahirdar city, Ethiopia.

\section{Institutional factors}

Effective waste management services would not be fully actualized until all actors of waste management partake and assume their individual responsibilities (Guerrero et al., 2013). Poor institutional coordination is another challenge that led to poor solid waste management in Halaba town. Similarly, UNEP (2010) in Bahir Dar city, Ethiopia found out that, institutional arrangement of the solid waste management has no integration or coordination and each sector is working independently.

\section{Technical factors}

There is no activity undertaken to convert waste to energy and reduce biodegradable solid waste at source in the town. In addition to this, the information obtained from sampled households indicated that most community of the study area are practicing open burning and open dumping as a major disposal methods. This indicates as more attention is not given on recycling and resource recovery as a common practice. Beside the location of solid waste disposal site of the town also indicates as no focus made on the environmental impacts of solid waste, because there is surface water around dump site. As a result it possible to mention technical factors as another cause of solid waste management problem of the study area. These finding is the exact reflection of finding reported by Feleke (2015).

Social factors

Public awareness and attitudes to waste can affect the whole municipal solid waste management system (Zurbrugg, 2003). The response obtained indicated that residents of the town have poor awareness regarding the environmentally friendly methods of solid waste management and the impact of inappropriate solid waste management system on their environment and health. Therefore, in addition to financial, institutional and technical factors, social factors are other challenges behind solid waste management problem. With similar research work Geofrey (2016) stated the fact that a lack of public awareness and co-operation are root causes of solid waste service delivery practices. Likewise in Halaba, one of the major problems behind poor solid waste management system is lack of awareness in communities.

\section{CONCLUSION}

The result of the study revealed that, solid waste generation rate of household is $0.271 \mathrm{~kg} /$ person/day. Furthermore, according to this study more than half of residential areas solid waste is composed of biodegradable solid wastes. This composition is very suitable to make compost. But, there is no activity made by the town SBPDD, as well as other actors towards application of this potential resource. The study also identified the existing practice of solid waste management of the town does not fulfill the required conditions for environmental safeguard due to this resulting in sanitation, social and environmental problems. Finally, the study revealed that the weak financial status of the municipality to provide adequate solid waste management service along with low awareness of the community were the series problem that challenges the practice of solid waste management system in Halaba town. So, based on the results of the study the following recommendations are forwarded:

Composting should be promoted since more than half of the refuse from households is biodegradable organic waste. 
Residents should start separating the waste at source itself into valuable components of municipal solid waste. SBPDD and health office of the town should engage in awareness creating campaign to enable the people aware of poor solid waste management practice.

Appropriate disposal site is needed with proper selection if not it should be well managed.

The study finding gives an insight for future researchers'. For instance:

Since, the existing solid waste disposal site is poorly designed and has various impacts on the local environment. Therefore, future researchers can select appropriate solid waste disposal site for the town using GIS with its multi criteria.

\section{Conflict of interests}

There is no any conflict of interest.

\section{REFERENCE}

Aboma F, Uttama R (2013). Community awareness of solid waste management practices: A case study from Ethiopia, Haramaya University, Ethiopia. Environment and We an International Journal of Science and Technology 8(2)

Achi HA, Adeofun CO, Gbadebo AM, Ufoegbune GC, Oyedepo JA (2012). An assessment of solid waste management practices in Abeokuta, southwest, Nigeria. Journal of Bio Chemistry 29(2): 177-188.

Asmamaw A, Tadesse L, Takele G, Tufa K, Wendwesen D (2017). Household solid waste generation rate and onsite handling practices in Debre Berhan town, Ethiopia. Science Journal of Public Health 5(1) :31-34.

Cochran G (1977). Sampling Techniques (3 ${ }^{\text {rd }}$ ed.). Wiley series in productivity and Applied Mathematical Statistics. New York, USA.

Desalegn M (2017). Assessment of solid waste management system in Nekemte town, East Wollega in Oromia region, Ethiopia. (Unpublished MSc thesis) Wollega University, Wollega, Ethiopia.

Duguma E, Tesfaye F, Amaha K, Abel B (2018). Municipal solid waste generation and disposal in Robe town, Ethiopia. Journal of the Air and Waste Management Association 68(12): 1391-1397

Feleke A (2015). Solid waste management in Durame town: Practice and challenges, Addis Ababa University, Ethiopia.

Geofrey O (2016). Challenges and possible interventions for effective solid waste management in Ngomongo village of Korogocho informal settlement, Nairobi, Kenya.

George DL (2015). Household solid waste management in Limbe Cameroon: Practices, problems and prospects, Pan Africa Institute for Development-West Africa.

Guerrero L, Maas G, Hogland W (2013). Solid waste management challenges for cities in developing countries. Waste Management 33(1): 220-232.

Halaba town health office annual report (2017).

Halaba town sanitation, beautification and parks development department (SBPDD) report (2017). Annual planned and executed activities report on solid waste management practice in Halaba town, Ethiopia. Unpublished material.

Halaba town socio economic data office annual report (2017).

Imam A, Mohammed B, Wilson DC, Cheeseman CR (2007). Solid waste management in Abuja, Nigeria. Center for environmental control and waste management, Department of Civil Engineering, University of Maiduguri, Maiduguri, Nigeria. Waste Management 28(2008):468-472.

Javaheri H (2006). Site selection of municipal solid waste landfills using analytical hierarchical process method in a geographical information technology environment in Giroft Iran. Journal of Environmental Health Science Engineering 3:177-184.

Koul L (1996). Methodology of Educational Research (2 $2^{\text {nd }}$ ed.). New Delhi: Vikas publishing house pvt. Ltd.

Koyachew E (2016). The problem of solid waste management and people awareness on appropriate solid waste disposal in Bahir Dar city, Amhara region, Ethiopia. Journal of Health and Environmental Sciences 3(1): 18.

Mengie B (2015). Solid waste generation and solid waste disposal site management in urban areas: The case of Dessie town, Amhara national regional state, Ethiopia. International Journal of Advanced Scientific and Technical Research 5(3): 293-307.

Mohammed G (2015). Assessing the current status of solid waste management: The case of Gondar town, Gondar University, Ethiopia. International Journal of Scientific \& Technology Research 4(9): 28-36.

NEMA (2007). State of the environment report for Uganda, National Environment Management Authority. Kampala: NEMA

Solomon C (2011). Assessment of municipal solid waste management service in Dessie town, MA thesis, school of graduate studies, Addis Ababa University, Ethiopia.

Tyagi V, Solomon F, Sharma HR (2016). Municipal solid waste management in Debre Berhan Ethiopia. Journal of Environment and Earth Science 4(5):98-103. 
Takele T (2004). Solid waste management for environment and occupational health students: In collaboration with the Carter Center, the Ethiopian Minister of Health and the Ethiopian Ministry of Education, Gonder University, Ethiopia Public Health Training Initiative. Gonder: EPHTI.

UNEP (2010). Solid waste characterization and quantification of Bahir Dar city for the development of an integrated solid waste management plan, United Nation Environmental Program. Bahir Dar: UNEP

Walhi J (2001). A long way to zero waste management. Proceedings of the waste-not- Asia conference, Taiwan, global alliance for incinerator alternatives.

Yeballework B (2014). Assessment of municipal solid waste management: The case of Hawassa town, Southern nation, nationalities and peoples regional state, Haramaya University, Ethiopia.

Yirgalem M (2005). Landfill management, its impacts on the local environmental and urban sustainability: The case of Repi land fill site, Addis Ababa, Ethiopia. Norwegian University of Science and Technology.

Zurbrug C (2003). Solid waste management in developing countries. 